\title{
ARANDU RENDA REKO: A VIDA DA ESCOLA GUARANI MBYA ${ }^{1}$
}

KALNA MARETO TEAO ${ }^{2}$

UFES

RESUMO: Este trabalho busca analisar as visões dos Guarani Mbya sobre a escola na aldeia indígena de Três Palmeiras, Espírito Santo. Partimos do pressuposto de que o entendimento da escola na aldeia deve-se a compreensão da cultura Mbya. Além disso, a escola como espaço exógeno à cultura guarani promove conflitos entre dois mundos distintos: a indígena e a da sociedade envolvente. Esses conflitos são marcados pela afirmação da identidade étnica dos Guarani, através do seu modo de ser ou nhandereko. As visões sobre a escola dividem-se basicamente de acordo com as variações dos grupos sociais da sociedade indígena em questão: mais velhos e lideranças políticas, os pais e a comunidade e os professores.

PALAVRAS-CHAVE: Guarani Mbya; educação escolar indígena; identidade étnica; índios.

ABSTRACT: This paper intends to analyze the visions of the Guarani Mbya on the school in the indigenous village of Três Palmeiras, Espirito Santo. According to the presupposition that the understanding of the school in the village is due to the comprehension of the Mbya culture. Moreover, the school as an exogenous space to the Guarani culture creates conflicts among two differents worlds: the native and the surrounding society. Those conflicts are marked by the statement of the ethnic identity of the Guarani, through their way of being or nhandereko. The visions of the school are divided according to the variations of the social groups in the indigenous society: the adults and the political leaderships, the teachers, the parents and the community.

KEYWORDS: Guarani Mbya; school education; ethnic identity; indigenous.

\section{A cultura ${ }^{3}$ guarani se faz persistente e resistente no espaço da escola. É muito comum a presença de pais, mães, mais velhos,}

\footnotetext{
${ }^{1} \mathrm{O}$ presente artigo consiste em uma parte da dissertação intitulada Arandu renda reko: a vida da escola Guarani Mbya, desenvolvida no Programa de Pós-Graduação em Educação da UFES (Universidade Federal do Espírito Santo).

${ }^{2}$ Mestre em educação. Pesquisadora em história indígena. E-mail: kalnamt@yahoo.com.br .

${ }^{3}$ Nesse sentido, Geertz (1989) analisa a cultura como um sistema entrelaçado de signos interpretáveis e encontra-se inserida dentro de um contexto descrito de forma inteligível e com densidade. A cultura é um sistema de relações complexas como uma teia que só adquire significado a partir da interpretação do todo.
}

Espaço Ameríndio, Porto Alegre, v. 2, n. 2, p. 83-97, jul./dez. 2008. 
lideranças políticas e crianças pequenas que acompanham as lições ou entram e saem livremente da sala de aula. As crianças aprendem em grupo. Caso não tenham interesse em algum conteúdo, elas saem e voltam, sem serem, por isso, repreendidas pelos professores. Crianças pequenas que ainda não estão em idade escolar ou que estudam em outro turno freqüentam a escola para levar alimentos aos irmãos e aprenderem junto com eles as lições do dia.

O professor ensina aos alunos juntamente com os mais velhos, considerados conselheiros e sábios. Os mais velhos costumam ir à sala de aula falar sobre as plantas medicinais e em seguida levam os alunos para as matas onde poderão vivenciar o que aprenderam na escola. Nessa atividade pedagógica, os alunos reconhecem as plantas medicinais e suas aplicações, além de desenvolverem a escrita na língua guarani e na língua portuguesa.

O tempo de ensino e aprendizado segue o ritmo dos Guarani ${ }^{4}$. Caso em uma aula não consigam terminar o que havia sido planejado, os professores e os alunos poderão levar até uma manhã inteira ou dias até que o conteúdo seja aprendido por todos.

O tempo para os Mbya obedece aos rituais religiosos e ao ritmo da natureza. As expressões que os Guarani utilizam para demarcar o tempo são: Ara Ymã (ano velho/inverno), Ara pyau (ano novo/verão), Ymã gware (antigamente), Aymã (hoje) e Are'i (pouco tempo). Para Borges (2002, p. 106), o tempo guarani deve ser pensado em relação à cosmovisão, aos mitos, aos tempos socioeconômicos e às novas temporalidades advindas das situações de contato, como a educação escolar e às novas práticas curativas dos postos de saúde. O autor afirma que o tempo serve para situar o sujeito nas sociedades, atuando como elemento formador das instituições e dos valores. Acrescenta ainda que o tempo imaginário ou social pressupõe a unidade da

\footnotetext{
${ }^{4}$ Segundo dados fornecidos pela FUNAI em 2005, os índios aldeados no Espírito Santo são 2.346, sendo 2.109 da etnia Tupinikim e 237 Guarani. Os Mbya residem em territórios dos Tupinikim em aldeias próprias em Tekoa Porã, Mboapy Pindo e Piraquê-Açu. Os Guarani Mbya chegaram ao estado do Espírito Santo em 1967, após uma longa caminhada que se iniciou em 1940, após disputa dos índios em torno da questão fundiária. Os Mbya foram forçados a retirarem-se de suas terras no Rio Grande do Sul, devido ao conflito com fazendeiros locais que desejavam se apropriar de suas áreas para o plantio de erva-mate. O grupo foi liderado pela xamã Tatãtxi Ywa Reté e sua família. Sobre a história dos Guarani e sua chegada ao estado confira Ciccarone (1996 e 2001).
} 
KALNA MARETO TEAO - Arandu renda reko ...

sociedade, sem o qual encontrar-se-ia em estado de dispersão contínua.

As aulas são ministradas em língua materna e em português. São estudados conteúdos específicos da realidade cultural e também referentes à cultura ocidental. Convivem no espaço da escola, a escrita do djuruá (branco) e a oralidade dos índios. Alguns materiais didáticos utilizados são produzidos pelos próprios professores indígenas e outros ditados pelo município.

Nesse sentido, a escola dos guarani pode ser entendida como espaço de fronteira onde ocorre o contato entre as diferentes etnias, em que as experiências e as tradições podem ser trocadas e reinventadas. De acordo com Tassinari:

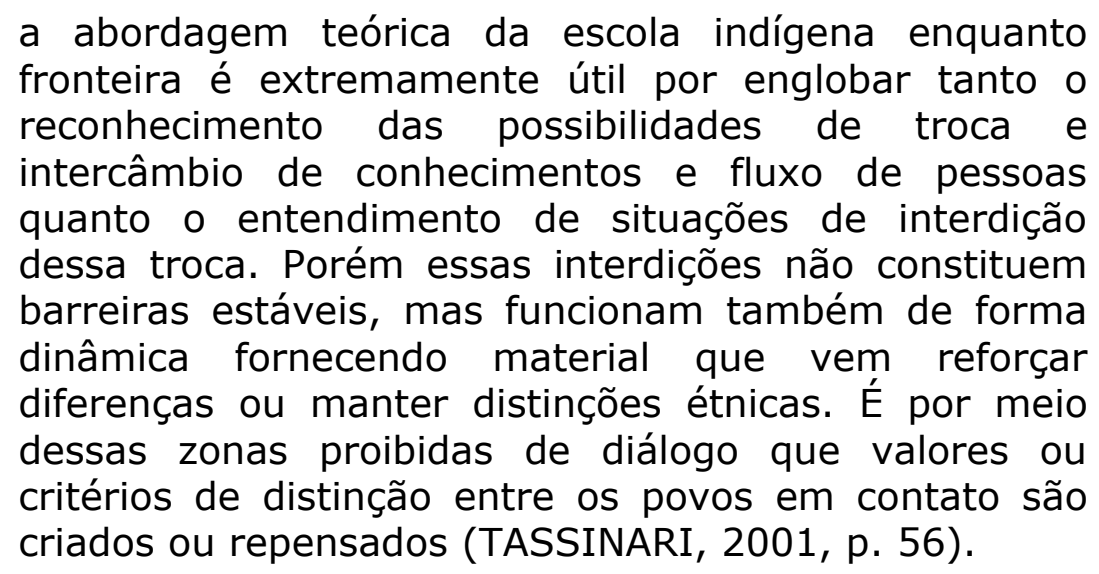

Tassinari (2001) acredita que as fronteiras da escola são flexíveis e dinâmicas, pois refletem o contato entre a sociedade indígena e a ocidental. Diante da possibilidade de troca de saberes e experiências entre os dois mundos ocorre também a ressignificação dos conhecimentos e das tradições. Por outro lado, a escola que poderia revelar apenas o universo ocidental, acaba por reforçar as tradições e a cultura indígena e passa a constituir-se como um espaço de interdição dos valores da cultura alheia, reforçando assim a cultura nativa.

Nas situações de contato dos índios com a sociedade envolvente ocorre o processo de afirmação da identidade étnica aqui entendida como uma forma de resistência dos indígenas para manter a identidade e a coesão do grupo diante das mudanças e transformações sociais, econômicas, políticas e culturais. De acordo com Manuela Carneiro da Cunha (1986, p. 117): “A identidade étnica de um grupo indígena é, 
KALNA MARETO TEAO - Arandu renda reko ...

portanto, exclusivamente função de auto-identificação e da identificação pela sociedade envolvente".

Os Guarani Mbya apresentam visões distintas sobre o papel da escola em suas aldeias e essas visões variam conforme os grupos sociais envolvidos, como os mais velhos e as lideranças políticas, os pais e os professores.

Para os mais velhos e as lideranças políticas a escola é apenas mais um espaço de educação guarani. É constante a referência aos processos próprios de aprendizagem dentro da cultura indígena. Nesse sentido, para os Mbya, um dos espaços primordiais para adquirir o conhecimento é a $O p y$, Casa de Rezas. Lá aprendem sobre a religião, a natureza e as normas de conduta social. Outro elemento central consiste na valorização dos mais velhos, considerados os verdadeiros professores e conselheiros. Para a liderança política de Mboapy Pindo:

As crianças já vão aprendendo carinho, amor com as pessoas, respeito com plantas, a educação com mais velhos, não entrar na casa dos outros à toa, não mexer com as coisas dos outros, não mexer com as plantas, não tirar plantas verdes, não consumir plantas verdes, entendeu? Ter respeito com os outros, entendeu? A geografia da vida através da explicação dos mais velhos, através da explicação do grande espírito. Ali que funciona tudo, os cânticos que as crianças aprendem são cânticos milenares. Então, cada conselho é supremo e o professor é o yraidjá, o conhecimento da nossa tradição, da reza e da dança, tudo é educação pra nós (WERÁ DJEKUPÉ, fevereiro de 2006).

O aprender para os Guarani não se restringe apenas a um espaço quer seja a escola ou a Opy, mas aprender está contido em diversas situações em que podem tirar alguma lição de vida. Nesse depoimento pudemos observar as regras sociais como o relacionamento do índio com a comunidade e os mais velhos. A relação dos Guarani com a natureza é de profundo respeito com os animais e as plantas, mesmo que estes sejam destinados para o consumo, pois acreditam que cada elemento vivo possui um espírito. A Casa de Rezas é o local onde os índios aprendem aspectos culturais e religiosos. 
KALNA MARETO TEAO - Arandu renda reko ...

Meliá (1979), em sua obra Educação indígena e alfabetização, estabelece a diferenciação entre educação indígena e educação para o indígena. Para Meliá, a educação indígena faz parte dos processos próprios de aprendizagem dentro da cultura nativa, isto é, a forma como o índio ensina a cultura e a tradição, através do seu modo de ser, dos costumes, da sua cosmologia, das relações sociais, da religião, dos mitos, dos ritos, das atividades da caça, da pesca e do artesanato. A educação é voltada para a vida e para a manutenção da cultura e da sociedade. Já a educação para o indígena, refere-se à utilização da escola como espaço de civilização e transmissão de saberes da cultura ocidental sobre os povos nativos, sendo utilizada desde os tempos da colonização, perdurando até às ações das missões religiosas em pleno século XX. No depoimento da liderança política de Tekoa Porã podemos observar a diferenciação entre a educação escolar e a educação indígena:

A escola deve partir sempre do conhecimento dos mais velhos para os mais novos, para a valorização da cultura. Deve haver respeito e união do professor, pais, alunos e comunidade para o fortalecimento da coletividade. As crianças têm que aprender a lidar com a mata, a usar instrumentos de caça e saber como caçar. Deve-se rezar para entrar na mata, tem que ver o horário, tem que entrar cedo antes do sol ficar alto. 0 saber milenar coloca também o horário. O dormir deve ser ao final da tarde. As crianças correm, brincam, andam durante a noite e isso não deve, parece normal, mas não é. Minha avó não sabia ler, mas era sábia e passava os ensinamentos. As crianças têm que aprender a coletividade, pois os povos indígenas são coletivos. Por exemplo, a caça deve ser dividida por todo mundo. Os costumes estão dentro do aprender. As crianças não estão praticando a caça e não conhecem a mata. Só aprender a ler e a escrever não é aprender as coisas concretas. Há muitos problemas na saúde por causa do consumo de alimentos industrializados. As parteiras hoje sentem dificuldades, pois não tem pessoas que aconselham as meninas durante a primeira menstruação. Não adianta falar em educação diferenciada, pois faltam muitas coisas. Deve haver o interesse dos pais e das mães para ensinar os costumes. É importante que os professores tenham reunião como os pais dos alunos e contar com o apoio dos caciques (WERÁ KWARAY, agosto de 2005). 
Neste depoimento podemos observar a referência às regras sociais, a sabedoria dos mais velhos, a vida em coletividade, os aspectos culturais e os conflitos advindos da situação de contato entre os índios e a sociedade envolvente. A educação indígena é entendida como um processo de aprendizagem no interior da própria cultura, como o respeito aos mais velhos, a relação com a natureza, a prática da caça, a relação com o tempo. Já a educação escolar aparece inserida em um mundo externo ao da aldeia juntamente com o consumo de alimentos industrializados, a leitura e a escrita.

A escola torna-se um espaço de afirmação da identidade étnica, por meio da afirmação do modo de ser guarani através da oposição guarani/ nós diante do djuruá/ outros. Mesmo sendo a escola um espaço exógeno à cultura guarani, ela apresenta uma grande complexidade, pois se torna ressignificada pelos Mbya como um dos espaços possíveis para a preservação da tradição ao mesmo tempo em que os mais velhos fazem a distinção entre escola, como espaço do branco em oposição a $O p y$, como o espaço do ensino verdadeiro da cultura, da religião e do modo de ser guarani.

Os pais e as mães guarani consideram a escola um local onde as crianças devem aprender primeiramente a língua portuguesa e os conhecimentos do mundo não indígena. Tal visão dos pais poderia ser considerada contraditória visto que o ensino em língua materna, com professores indígenas e com processos próprios de aprendizagem constituíram-se como as principais bandeiras das comunidades indígenas em relação à educação nas aldeias.

No entanto, o que observamos foi uma mudança do sentido da escola para os índios guarani no Espírito Santo. Se anteriormente à década de 90 , os Mbya rejeitavam a implantação das escolas por considerarem uma instituição civilizatória, nos tempos atuais, a escola foi ressignificada como espaço instrumental na medida em que possibilita aos índios mecanismos de defesa política e oportunidades de igualdade social diante do mundo ocidental.

Nessa perspectiva, acreditamos que a escola indígena possui dois eixos norteadores que são a perspectiva da diferença e da interculturalidade. Para Nascimento (2004, p. 17), o conceito de 
KALNA MARETO TEAO - Arandu renda reko ...

diferença configura-se como um eixo curricular que promove o diálogo, a mediação reflexiva, reinventa a escola para as populações indígenas e ressignifica as práticas pedagógicas. A apropriação do conceito de diferença remonta à concepção do índio como sujeito e protagonista de sua própria história marcada por incessantes lutas pelo reconhecimento da alteridade e da pluralidade étnica. Compreendemos a educação intercultural ${ }^{5}$ de acordo com a visão de Gilberto F. da Silva:

A noção de interculturalidade, além de expressar a coesão de um grupo social, proporcionando condições para o fortalecimento da identidade cultural, vai estimular a aquisição do conhecimento cultural de outros povos. Isso significa que não houve uma transição de termos conceituais, mas uma mudança no tratamento da pluriculturalidade no espaço da escola. Das preocupações marcadamente lingüísticas, características da educação intercultural e bilíngüe, a interculturalidade considera o contexto sociocultural dos alunos (SILVA, 2003, p. 41-42).

A educação intercultural não se restringe apenas a aspectos da questão lingüística, mas se refere ao contato e à apropriação das diferentes culturas de forma concreta no espaço escolar e também nas relações sociais. Os índios acreditam que a escola pode thes fornecer o conhecimento do mundo djuruá e dessa forma conseguirão relacionarse em condições de igualdade com a sociedade envolvente. Por exemplo, o domínio da língua portuguesa permite que consigam se comunicar quando precisam ir ao hospital, ao comércio e à cidade. Também possibilita que conheçam melhor o mundo da escrita através do entendimento de leis e que não sejam lesados nos cálculos durante a

\footnotetext{
${ }^{5}$ Silva (2003) estabelece três modelos de educação intercultural: o modelo tecnológico, o hermenêutico e o crítico. O modelo tecnológico defende a compensação dos déficits das culturas minoritárias, capacitando-as e instrumentalizando-as através do ensino da língua majoritária. O modelo hermenêutico ou interpretativo propõe a reflexão de alunos e professores sobre as práticas discriminatórias e o reconhecimento da diversidade cultural. O modelo crítico ou sóciopolítico preocupa-se com a modificação de situações sociais, culturais e ideológicas que causam a discriminação racial e propõe a busca por transformações profundas na sociedade. Este modelo reconhece os conflitos entre as culturas e preconiza o diálogo entre elas como possibilidade de convivência, além do reconhecimento da diversidade e da perspectiva interdisciplinar do currículo. Na América Latina, o termo bicultural foi utilizado para denominar as ações institucionais que enfatizavam a diferença cultural dos alunos, através de projetos de educação bilíngüe em culturas indígenas. No Chile, na Colômbia, no México e na Guatemala destacaram-se projetos e debates relacionados ao bilingüismo, ao ensino da cultura, à utilização de materiais próprios.
}

Espaço Ameríndio, Porto Alegre, v. 2, n. 2, p. 83-97, jul./dez. 2008. 
KALNA MARETO TEAO - Arandu renda reko ...

venda de artesanato. De acordo com as mães, a escola no espaço da aldeia consiste em um meio de comunicação com o mundo exterior, conforme podemos observar nos depoimentos a seguir:

A escola é muito importante para as crianças porque mais pra frente vão ser o futuro. Eles vão aprendendo muito pra trazer muitas coisas importantes pra aldeia. Aprender na escola não esquecer a língua e não perder a cultura da gente e outros estudos como o português pra não ter dificuldade. Quando sair lá fora, falar bem o português e trazer informações para aldeia (KERETXU POTY, fevereiro de 2006).

A escola é boa e é pertinho. Antes, eu não deixava as crianças estudar porque tinha que ir lá fora. Agora as crianças estudam na aldeia, isso vai ajudar muito porque as crianças não vão passar dificuldade porque não entendem o português, As crianças não vão ficar dependendo de outras pessoas. Lá em Santa Catarina não falava português porque minha avó não deixava estudar (ARA POTY, fevereiro de 2006).

Os pais acreditam que a escola constitui-se como espaço gerador de ascensão social, constituindo-se como o locus preparatório para que os filhos exerçam profissões de prestígio na sociedade envolvente, como médicos, advogados, dentre outros. Afirmam que o índio de posse dos mesmos conhecimentos que os brancos, possuem igual capacidade para exercer uma profissão. Ao afirmarem a sua identidade étnica, os Guarani opõem-se a situações de descaso e preconceito vivenciados diariamente e lutam contra os estereótipos de índio preguiçoso, incapaz, inferior e atrasado ${ }^{6}$.

A educação escrita ajuda para o futuro, a criança depois que avançar, pode avançar na cultura guarani porque sem estudo, sem saber ler, a gente sempre viveu em inferioridade. Os governantes não reconhece os índios como pessoas capazes, os mais velhos querem que os jovens voltem para o estudo, porque disso os povos guarani é reconhecido. Sem estudo como vão conseguir ler, escrever, entender o que se tá passando lá fora. Se a escrita está defendendo os

\footnotetext{
${ }^{6}$ Para Freire (2002, p. 97-98) existem cinco equívocos que foram enraizados ao longo da história pela sociedade brasileira e contribuem para perpetuar o preconceito e a discriminação sobre os índios, sendo considerados como: culturas atrasadas, culturas congeladas, índio genérico, o índio no passado e o brasileiro não é índio.
}

Espaço Ameríndio, Porto Alegre, v. 2, n. 2, p. 83-97, jul./dez. 2008. 
KALNA MARETO TEAO - Arandu renda reko ...

índios para eles saberem para essa época e para o futuro (KWARAY HATÁ MIRI, março de 2006).

Bergamaschi (2005) percebe que a escolarização para os Guarani do Rio Grande do Sul assume um caráter ambíguo, revelando porque os Mbya ao mesmo tempo desejam e não desejam a instituição na aldeia. Para a autora, a escola apresenta-se como espaço de fronteira, em que os Guarani a desejam para poder se relacionar com a sociedade envolvente, apropriando-se do ensinamento da escrita e da língua portuguesa. Ao mesmo tempo em que essa escola ensina o currículo da sociedade envolvente, reforça aspectos da tradição, da cultura e da cosmologia guarani em seu espaço. Contudo, os Mbya, sabendo da necessidade da escola, temem que a mesma instituição os faça alterar o seu modo de vida tradicional.

Vieira (2006), ao analisar o contexto dos Guarani em Santa Catarina, aponta que para os Mbya, a escola apresenta dois papéis fundamentais. Primeiramente, os Guarani compreendem a escola como espaço necessário de apropriação da leitura e da escrita, como forma de se instrumentalizar diante da sociedade envolvente. Por outro lado, os Guarani atribuem à escola um papel de resgate cultural, diante do "aculturamento dos mais jovens", em virtude do contato com a sociedade não índia.

Para entender a aculturação faz-se necessário compreender o processo histórico de produção do conceito. Segundo Wachtel (1976, p. 113), a aculturação relacionava-se ao surgimento da Antropologia enquanto ciência. Seu objeto de estudo, os povos não europeus, eram considerados inferiores, primitivos e atrasados. O aculturado confundiase assim com o evoluído, isto é, o nativo tornava-se integrado ao modelo ocidental. Embora o autor trabalhe o período colonial dos povos indígenas na América, sua análise torna-se pertinente para tornar complexo o uso do termo aculturação. Para Watchel, a aculturação apresenta em si dois processos principais: a aculturação imposta e a espontânea. A aculturação imposta decorre do uso da violência, com maior presença da dominação da cultura externa. Já a aculturação espontânea remete a um movimento inverso, as culturas nativas apropriam-se de elementos da cultura externa e a adaptam à sua estrutura social, econômica e política. O processo de aculturação 
KALNA MARETO TEAO - Arandu renda reko ...

espontânea promove em seu interior outros dois movimentos: a integração e a assimilação. Para o autor:

No processo de integração, os elementos estranhos são incorporados ao sistema indígena, que os submete a seus próprios esquemas e categorias; mesmo se provocam mudanças no conjunto das sociedades, essa reorganização adquire sentido no interior dos modelos e valores autóctones. (...) No outro pólo, o processo de assimilação realiza o fenômeno inverso: a adoção de elementos europeus se acompanha da eliminação das tradições indígenas, submetendo-se aos modelos e valores da sociedade dominante; ao final dessa evolução, a identidade étnica se dissolve nas variantes da cultura ocidental (WACHTEL, 1976, p. 118-119).

Criticando o conceito de aculturação, Roberto Cardoso de Oliveira (2000) prefere a utilização do termo fricção interétnica para designar o contato entre culturas distintas e ultrapassar os esquematismos antropológicos de sistemas fechados, estáticos e em equilíbrio:

\begin{abstract}
Chamamos "fricção interétnica" o contato entre grupos tribais e segmentos da sociedade brasileira, caracterizado por seus aspectos competitivos e, no mais das vezes conflituais, assumindo esse contato proporções "totais", isto é, envolvendo toda a conduta tribal e não-tribal que passa a ser moldada pela situação de fricção interétnica (OLIVEIRA, 2000, p. 46).
\end{abstract}

Para Macedo e Farage (2001, p. 186), a escola é parte constitutiva do Estado nacional, mas esse aspecto, no entanto, é velado quando passam entender a escola como espaço da produção e reprodução da cultura. Para as autoras, a escola busca apropriar-se de um local que não lhe pertence, isto é, a cultura indígena. E para ser considerado parte da cultura é preciso que existam meios eficientes de produção e reprodução de conteúdos significativos. Criticam a visão da escola com função de resgate cultural por acreditarem que tal pensamento deriva de uma corrente hegemônica e conservadora que incorre no equívoco de reduzir a cultura a meros conteúdos a serem estudados e não vivenciados. Afirmam ainda que historicamente tem-se verificado que as minorias étnicas conseguem manter sua dinâmica cultural mesmo diante de contextos de opressão política. 
KALNA MARETO TEAO - Arandu renda reko ...

Os professores guarani ${ }^{7}$ compreendem a escola como um espaço de ensino da cultura indígena e não indígena. Acreditam que a instituição exógena pode recuperar os aspectos da tradição e da cultura considerados perdidos, conforme podemos observar através da afirmação da professora:

O ensino deveria voltar mais para a cultura, porque hoje em dia, alguns não sabem pescar, capinar e a importância da plantação, então fica difícil. Fazer tipo de armadilha, ter aula prática para ensinar armadilha. Hoje em dia, as crianças nem conhece andar na trilha e ver o tipo de remédio, não tem plantação (KERETXU RETÉ, julho de 2006).

Os professores acreditam que devem ensinar tanto a cultura nativa como a cultura da sociedade envolvente. Assim como os pais, pensam que a escola possibilita a aquisição dos conhecimentos do mundo não indígena, como o domínio do português, e, dessa forma poderão ter condições de lidar com a sociedade ocidental e enfrentar o preconceito.

Tem pouco material didático guarani feito pelos próprios educadores da aldeia. Quando estudar o livro vê o artesanato e o material. O material didático usado do djuruá é importante estudar o português e o ensino das disciplinas dos djuruá porque os alunos sofrem o preconceito. Acho que tem que ensinar o português para escrever e ler bem pra poder lida com o djuruá (TUPÃ ARAY, março de 2006).

Os professores possuem em comum com os alunos os relatos de preconceitos vividos ao estudarem em escolas não índias, conforme podemos verificar nos depoimentos que se seguem:

Às vezes tem aquela discriminação por ser índio, sempre tem. Por isso que é bom ter uma escola dentro da aldeia, porque tem aquela discriminação. Aí tem aquela pessoa que diz porque é índio não dá muita importância. Porque é índio aceita qualquer coisa.

\footnotetext{
${ }^{7}$ Segundo dados contidos nas Estatísticas sobre educação escolar indígena (2007), no Espírito Santo existem cerca de 39 professores indígenas que atendem sete escolas municipais e um total de 587 alunos matriculados. Dos 39 professores, 16 possuem o ensino superior completo com licenciatura, 16 o ensino médio completo com magistério, 4 apresentam nível médio completo e 3 possuem apenas o ensino fundamental. Os guarani possuem duas escolas, sendo que uma situa-se em Mboapy Pindo e a outra em Tekoa Porá.
}

Espaço Ameríndio, Porto Alegre, v. 2, n. 2, p. 83-97, jul./dez. 2008. 
KALNA MARETO TEAO - Arandu renda reko ...

Então a diferença é essa. Porque tem essa discriminação e índio sempre tem dificuldade pra aprender. Tanto dentro da aldeia como na escola de fora, sempre tem essa dificuldade. Por isso tem que é bom começar sempre dentro da aldeia, pra você aprender, ver como é o lado de fora, as regras, por causa que, na verdade eu comecei fora da aldeia (...) (ARA'Í, fevereiro de 2006).

Bom, estudei de $1^{a}$ a $4^{a}$ série na aldeia e estudei de $5^{a}$ a $8^{a}$ em escola não índia. Mais ou menos, foi bom sim. Foi meio difícil porque a gente fala duas línguas. Fica mais complicado pra gente entender. Mesmo português, a gente tem que entender em guarani, pra depois responder as perguntas, fazer as tarefas, aí ficava mais difícil, né. Discriminação a gente sempre enfrenta. Até hoje sofre um pouco. Tem gente que não gosta de índio. Fala que índio é feito bicho e não sei o quê. A gente já tá até acostumado com isso. E hoje é a mesma coisa (KARAÍ DJEKUPÉ MIRIM, fevereiro de 2006).

Estudei em escola não índia. Por um lado foi bom e por outro foi um desafio, porque a gente é muito discriminado. Eu mesmo briguei em Coqueiral e em Rio Bananal, pros próprios colegas meus não me inferiorizar. Agora eu luto pela minha defesa e pela defesa do meu povo, pela nossa cultura. Antigamente eu não tinha palavras e nem tinha argumentos. Hoje, se as pessoas me criticarem eu tenho argumentos, coragem e argumentos e dizer que sou índio e a cultura que tenho. E por quê? Antes, não tinha argumentos, antes aceitava as críticas negativas. Hoje não! Hoje eu brigo mesmo pela nossa cultura e tenho orgulho de ser índio, de ser um povo diferente (KARAÍ, fevereiro de 2006).

A maioria dos Guarani antes de exercer a função de professor, trabalhava em atividades nas quais ocorria o contato com a sociedade envolvente, como agentes de saúde. A inserção dos Mbya no universo da educação escolar possibilitou-lhes a ascensão econômica e política em suas comunidades, pois desempenhavam assim como os demais, atividades relacionadas à agricultura e ao comércio do artesanato.

Os mais velhos e os caciques agem tentando evitar conflitos internos advindos da posição de prestígio político que os professores ocupam dentro da comunidade indígena, pois emergem como novas 
KALNA MARETO TEAO - Arandu renda reko ...

lideranças. Os professores antes de tomarem quaisquer decisões devem consultar os mais velhos primeiramente. Além disso, os mais velhos comentam sobre a postura do professor que deve seguir os preceitos e as normas da vida coletiva conforme depoimento da liderança política da aldeia de Tekoa Porã:

Falo nas reunião que o professor se vai dar aula no dia seguinte tem que entender, estudar e preparar aula que vai dar, tem que conhecer. Hoje em dia tem que aprender porque tem cidade perto, tem que aprender fora da aldeia pra lidar com o branco, isso criança tem que aprender. Se tiver uma festa, ou um forró, os amigos chama pra sair, o professor tem que pensar, pedir pros mais velhos e não ficar a noite fora, não beber bebida alcoólica, não ir pro baile. Nas reunião fala com os professor pra se for dar aula no dia seguinte não ir às vezes pro forró, ficar e preparar a aula (TUPÃ KWARAY, março de 2006).

Os professores guarani ${ }^{8}$ são escolhidos por suas comunidades para lecionarem nas aldeias de acordo com os seguintes critérios: o envolvimento e a dedicação aos interesses da comunidade, o conhecimento da realidade sócio-cultural dos alunos, o domínio da língua materna e da língua portuguesa na oralidade e na escrita e o conhecimento da cultura indígena e da cultura nacional.

As múltiplas visões dos Mbya sobre a escola revelam ao mesmo tempo a persistência da cultura guarani, as contradições e os conflitos resultantes das situações de contato entre o universo indígena e não indígena. Por outro lado, traz à tona a possibilidade de uma reinvenção da escola que antes civilizava e agora é entendida como um espaço político de afirmação da identidade étnica, de aquisição de conhecimentos, de oportunidades e de inserção social.

Os Guarani reinventam a escola a partir da perspectiva da sobrevivência de uma minoria étnica diante de um universo cultural distinto e historicamente desigual. Aprendem com a experiência ao

\footnotetext{
${ }^{8}$ Atualmente, existem cerca de seis professores guarani que ministram aulas até a quarta série nas aldeias. Dentre os seis professores, apenas dois são concursados. Três professores realizaram o magistério indígena em Aracruz e outros três cursam o magistério indígena Kuaa Mbo'e = Conhecer / Ensinar. A partir da quinta série atuam nas escolas aproximadamente sete professores tupinikim. Todos são contratados pelo poder municipal. Um dos professores possui licenciatura indígena cursado pela UNEMAT. Os demais professores não possuem licenciatura, mas cursos em áreas afins, como secretariado executivo, direito, ciências contábeis, arquitetura.
}

Espaço Ameríndio, Porto Alegre, v. 2, n. 2, p. 83-97, jul./dez. 2008. 
KALNA MARETO TEAO - Arandu renda reko ...

longo de quinhentos anos que mesmo com o preconceito, o descaso, a discriminação a que são submetidos cotidianamente, não se deixam abater e usam os mesmos instrumentos que antes os civilizavam, reapropriando-se deles e transformando-os em novas possibilidades de sobrevivência e de convivência com outras alteridades.

\section{Referências bibliográficas}

BERGAMASCHI, Maria Aparecida. Nhembo'e! Enquanto o encantamento permanece! Processos e práticas de escolarização nas aldeias Guarani. 2005. 270 f. Tese (Doutorado em Educação) - PPGE, UFRGS, [2005].

. Por que quer em e por que não quer em escola os Guarani? Tellus, Campo Grande, v. 4, n. 6, p. 107-120, abr. 2004.

BORGES, Luiz C. Os Guarani Mbya e a categoria tempo. Tellus, Campo Grande, v. 2, n. 2, p. 105-122, abr. 2002.

CARNEIRO DA CUNHA, Manuela Antropologia do Brasil: mito história e etnicidade. São Paulo: Brasiliense, 1986.

CICCARONE, Celeste. Drama e sensibilidade: migração, xamanismo e mulheres mbya guarani. 2001. 296 f. Tese (Doutorado em Ciências Sociais) - Programa de Estudos de Pós-graduação em Ciências Sociais, PUC-SP. [2001].

(Org). Memória viva Guarani: revelações sobre a terra - Comunidade Tekoa Porã. Vitória: UFES, 1996.

CLASTRES, Pierre. A sociedade contra o Estado. 5.ed. Francisco Alves, 1990.

ESTATÍSTICAS SOBRE EDUCAÇÃO ESCOLAR INDÍGENA. Brasília: INEP, 2007.

FERREIRA, Mariana K. L. A educação escolar indígena: um diagnóstico crítico da situação no Brasil. In: SILVA, Aracy Lopes da.; FERREIRA, Mariana K. (Orgs.). Antropologia, História e Educação: a questão indígena e a escola. 2.ed. São Paulo: Global, 2001, p. 71-111.

FREIRE, José R. B. A imagem do índio e o mito da escola. In: MARFAN, Marilda Almeida (org). Congresso brasileiro de qualidade na educação: formação de professores: educação indígena. Brasília: MEC/SEF, 2002, v. 4, p. 93-99.

GEERTZ, Clifford. A interpretação das culturas. Rio de Janeiro: LTC, 1989. 
KALNA MARETO TEAO - Arandu renda reko ...

LADEIRA, Maria Inês. O caminhar sob a luz: o território mbya à beira do oceano. 1992. 199 f. Dissertação (Mestrado em Ciências Sociais) - Programa de Estudos de Pósgraduação em Ciências Sociais, PUC-SP. [1992].

. Espaço Geográfico Guarani-Mbya: significado, constituição e uso. 2001. 270 f. Tese (Doutorado em Geografia Humana) - USP. [2001].

LADEIRA, Maria Inês; MATTA, Priscila (Orgs.). Terras guarani no litoral: as matas que foram reveladas aos nossos antigos avós. Ka'a güy oreramói kúery ojou rive vaekue ÿ. São Paulo: CTI, 2004.

MACEDO, Ana V.L. da S; FARAGE, Nádia. Construção de histórias, ensino de história: algumas propostas. In: SILVA, Aracy Lopes da; FERREIRA, Mariana K. L. (Orgs.). Práticas pedagógicas na escola indígena. São Paulo: Global, 2001, p. 185207.

MELIÁ, Bartolomeu. Educação indígena e alfabetização. São Paulo: Loyola, 1979.

NASCIMENTO, Adir Casaro. Escola indígena: palco das diferenças. Campo Grande: UCDB, 2004.

OLIVEIRA, Roberto Cardoso de. O trabalho do antropólogo. 2.ed. Brasília: Paralelo/ São Paulo: UNESP, 2000.

SILVA, Gilberto F. da. Multiculturalismo e educação intercultural: vertentes históricas e repercussões atuais na educação. In: FLEURI, Reinaldo Matias. Educação intercultural: medicações necessárias. Rio de Janeiro: DP \& A, 2003, p. 17-52.

TASSINARI, Antonella M. I. Escola indígena: novos horizontes teóricos, novas fronteiras de educação. In: SILVA, Aracy Lopes da; FERREIRA, Mariana K. Antropologia, História e Educação: a questão indígena e a escola. 2.ed. São Paulo: Global, 2001, p. 44-70.

VIEIRA, Ismênia de F. Educação escolar indígena: as vozes guarani sobre a escola na aldeia. 2006. 183 f. Dissertação (Mestrado em Educação) - PPGE, UFSC. [2006].

WATCHEL, Natan. A Aculturação. In: LE GOFF, Jacques; NORA, Pierre. História: novos problemas. Rio de Janeiro: Francisco Alves, 1976, p. 113-129. 